Artigo

\title{
Reunião conjunta da Liga Acadêmica de Medicina Interna e da Associação Amigos do HU: "O que você sabe sobre o infarto do miocárdio?"
}

\author{
Ana Vitória Coppoli Silva', Gustavo Peressoni Bernard', Giulia Gabriela Norcio Scapini', Nathana Thuane \\ Müller Loebens' \\ 1. Estudante do Curso de Graduação em Medicina, Centro de Ciências da Saúde, Universidade Federal de Santa Catarina (UFSC), \\ Campus Reitor João David Ferreira Lima, Florianópolis, Brasil.
}

\begin{abstract}
RESUMO
Comunicação breve de atividade de extensão realizada pela Liga Acadêmica de Medicina Interna, em novembro de 2019, com educação à comunidade externa sobre sintomas de alerta e medidas de socorro iniciais para o infarto do miocárdio.
\end{abstract}

DOI: https://doi.org/10.32963/bcmufsc.v6i1.3900

Indexadores: Infarto do miocárdio; Doenças Cardiovasculares; Relações Comunidade-Instituição; Comunicação Submetido em 15/01/2020; aceito para publicação em 23/05/2020.

Os autores negam conflitos de interesse.

Autor para contato: Ana Vitória Coppoli Silva. E-mail: anavitoriacoppoli@gmail.com

Na última quarta-feira (dia 27) do mês de novembro de 2019, aconteceu no Bloco Didático do Hospital Universitário da UFSC o encontro entre a Liga Acadêmica de Medicina Interna (LAMI) e a Associação Amigos do HU (AAHU), que teve como tema "Infarto Agudo do Miocárdio (IAM)”. Organizado pelos alunos da diretoria da LAMI, na oportunidade foi oferecido aos participantes da AAHU um espaço de informação e de discussão sobre um tema tão importante para a saúde da população.

O encontro foi conduzido pelos alunos do curso de Medicina UFSC, Ana Vitória Silva e Gustavo Bernard, com o apoio das alunas Giulia Scapini e Nathana Loebens, e iniciou com a pergunta: por que falar sobre IAM? Essa pergunta pode ser facilmente respondida com os seguintes dados: segundo informações do Ministério da Saúde, infarto agudo do miocárdio se configura como a principal causa de morte na população brasileira atualmente, sendo que, somente em 2016, o número de óbitos secundários ao IAM no Brasil chegou a mais de 180 mil mortes. Além disso, o perfil epidemiológico da população brasileira está em processo de mudança, com um constante aumento da população idosa e, consequentemente, aumento no número de condições crônicas, como doenças cardiovasculares. É de extrema importância que a população tenha conhecimento desta condição grave, mas muitas vezes prevenível, e saiba que quanto mais rápido for reconhecida e tratada, melhor a chance de haver menos sequelas.

Durante o encontro foram discutidos conceitos, fisiopatologia, fatores de risco, diagnóstico, tratamento e prevenção do IAM, sempre de uma forma didática e compreensível para todos. Após essa fase expositiva foi então aberto um espaço para dúvidas e discussão, em que os participantes do encontro puderam esclarecer suas dúvidas sobre o tema e compartilhar algumas experiências pessoais.

O encontro foi encerrado deixando uma importante mensagem final: prevenir e reconhecer um infarto agudo do miocárdio pode salvar vidas, mesmo que você não seja profissional da saúde. É muito importante que haja espaços de debate como esse para a população se informar sobre essa e outras condições comuns e graves que afetam a saúde. A LAMI, apesar de ser voltada para os alunos da Medicina, não deixou de lado essa parte de prevenção e promoção da saúde, que deve ser voltada para a população, o que muitas vezes é esquecida por profissionais da saúde, apesar de sua extrema importância. 


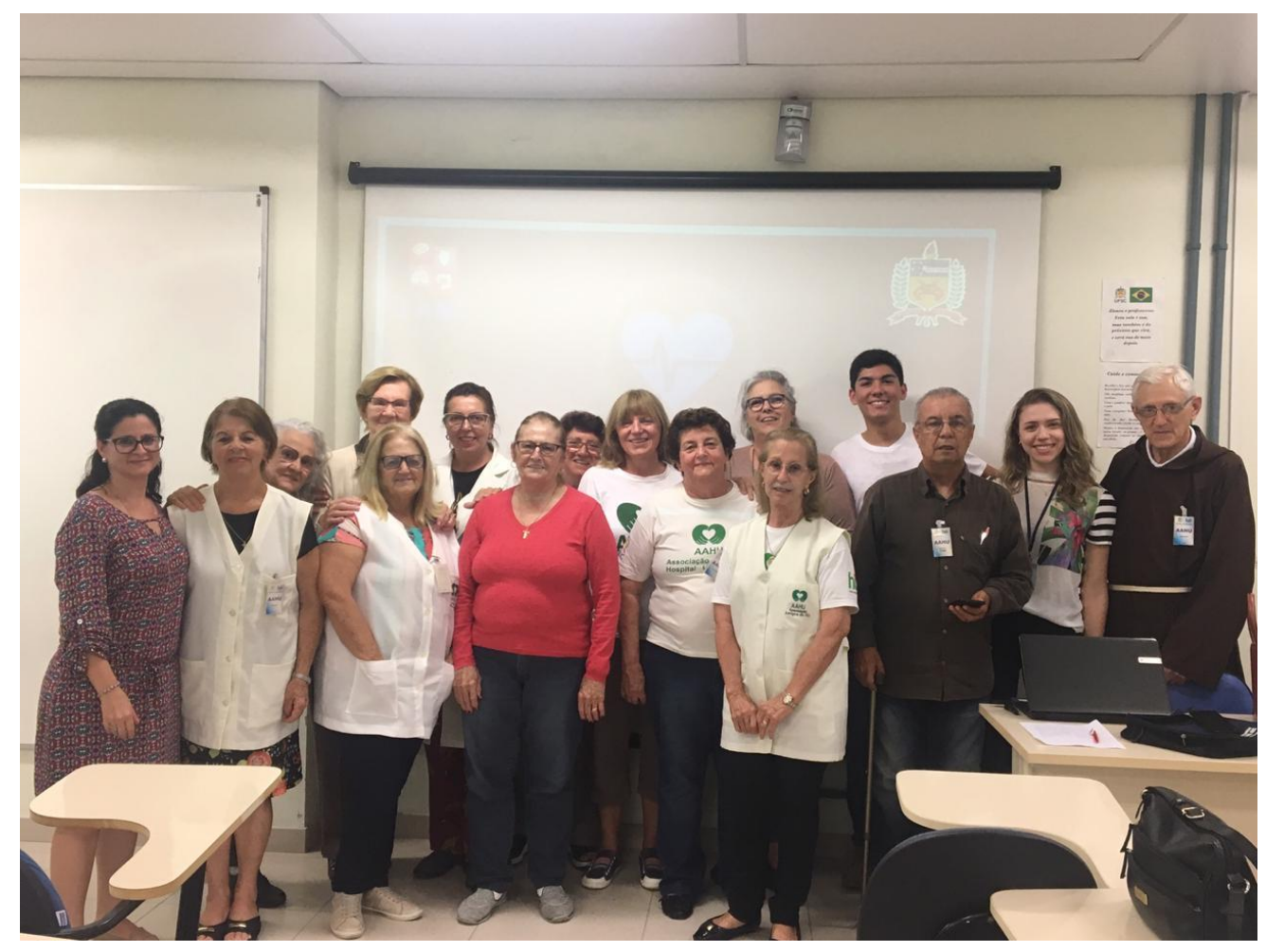

Figura 1. Diretoria da Liga Acadêmica de Medicina Interna e o grupo da Associação Amigos do HU, na reunião conjunta de 27 de novembro de 2019. O terceiro a partir da direita é o Sr. Pedro Camacho dos Santos, presidente da AAHU. A seu lado estão Gustavo Bernard e Ana Vitória Silva, acadêmicos da LAMI.

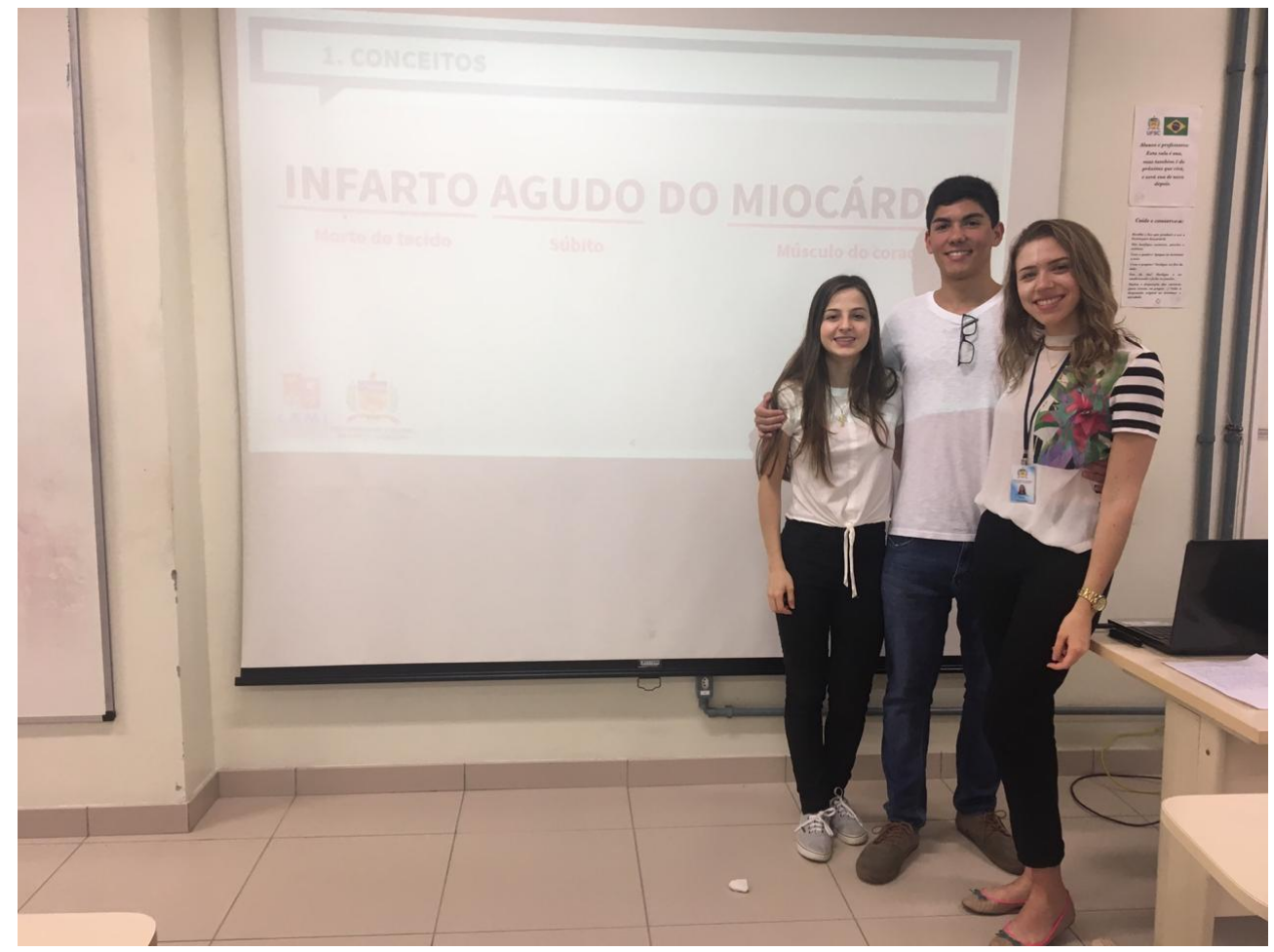

Figura 2. Giulia Scapini, Gustavo Bernard e Ana Vitória Coppoli. Diretoes da LAMI e organizadores do encontro.

Nota do Editor: Nesta publicação desejamos registrar o reconhecimento do "Boletim" ao Sr. Pedro Camacho dos Santos, presidente da Associação Amigos do Hospital Universitário, que tanto contribuiu com seu trabalho voluntário para a melhoria dos serviços do HU. Falecido em 8 de maio de 2020, deixa grande legado com a AAHU e exemplo a todos que o conheceram. 